


\section{Introducción al Marketing Político}

Gina EnCISO Granados ${ }^{1}$

\section{Definición de marketing político}

El marketing político intenta persuadir a los ciudadanos para que acudan a las urnas y voten por un candidato o partido concreto. Aun así, para lograr esto, el mensaje del candidato tiene que influir en las creencias y las actitudes del individuo. (Salgado, 2002, p. 22)

La estructura del marketing comercial puede ser aplicada al marketing político con las necesarias adaptaciones, aunque en este tema existen opiniones diferentes, pues "con todo, la homologación total

1 Profesional en Publicidad de la Universidad Jorge Tadeo Lozano, Especialización en Gerencia de Mercadeo de la Universidad Externado de Colombia. MBA magíster en Dirección y Administración de Empresas - Máster en Dirección Comercial y Marketing - EUDE Business School - España. Experiencia en dirección, planificación y ejecución de estrategias comerciales, planes de mercadeo, campañas de publicidad, coordinación de investigaciones de mercado, gestión de marketing digital y relaciones públicas para empresas nacionales y multinacionales. Docente de Publicidad y Relaciones Públicas, coordinadora del programa de acompañamiento estudiantil; directora del programa de radio 100 \% Marketing; coordinadora del consultorio de marketing de la Facultad de Mercadeo de la Universidad Santo Tomás. 
entre el marketing comercial y el político es una opción errónea" (Aria, 2015). Si bien es cierto que la actividad política se concibe con particularidades muy diferentes a las de la actividad comercial, la teoría que se ha desarrollado en el marketing comercial ha tenido que adaptarse a múltiples ámbitos y esto ha ocasionado que se consolide como modelo.

De esta manera, se tiene el marketing social, definido por Andreasen (1995) como la aplicación de las técnicas del marketing para analizar y plantear programas que influyan en el comportamiento de un público objetivo; el marketing educativo, el cual Manes (1993) enfoca al conocimiento de las necesidades sociales para satisfacerlas con proyectos educativos; el marketing público, orientado a los programas de entidades del gobierno y aunque carezcan de una orientación comercial y aún sea incipiente su uso, existe la necesidad de ofrecer un mejor servicio al cliente, por lo cual se tendrá que estimular su aplicación.

Todos estos ámbitos han encontrado, en las técnicas del marketing, herramientas que les permiten llegar con sus propuestas al público que desean impactar. Para ello, "el marketing se ocupa de identificar y satisfacer necesidades humanas y sociales” (Kotler, 2002, p.2), y esta función se aplica tanto a los planteles educativos y entidades públicas como a los partidos políticos y candidatos; inclusive dentro de la misma empresa se aplican las técnicas del marketing para "vender" la empresa a sus empleados, el denominado endomarketing, con el objetivo de generar una buena imagen de la organización con los empleados, que consecuentemente proyectarán hacia el exterior.

Neil Borden introdujo el concepto del marketing mix o mezcla de mercadeo en la década de los 50, a través de doce variables: planeación del producto, precio, marca, canales de distribución, personal de ventas, publicidad, promoción, empaque, exhibición, servicio, distribución, investigación.

El profesor E. Jerome McCarthy, en 1960, redujo a cuatro elementos las anteriores variables, desarrollando el conocido concepto de las 4P del marketing: producto, precio, plaza y promoción. 


\section{Del marketing comercial al marketing político}

Es necesario aclarar las diferencias entre marketing político y marketing electoral. El primero se refiere al marketing permanente de los partidos, el que desarrollan para mantenerse en contacto con los habitantes de su región, ciudad o país, independientemente de los periodos electorales. El segundo es el plan que se ejecuta por un candidato en un espacio de tiempo determinado con el objetivo de ganar los votos necesarios para obtener un cargo de elección popular.

Aunque se ha insistido en diferenciar la utilización de las técnicas del marketing comercial en el marketing político, son varias las razones que existen para aplicar esta disciplina a las actividades políticas y electorales, entre las cuáles Luque resalta:

El desarrollo de las técnicas para la obtención de información preelectoral y postelectoral (investigación de marketing), el estudio del electorado (comportamiento del consumidor), el posicionamiento ante otras, la utilización planificada y masiva de los medios de comunicación, la gestión profesionalizada de las campañas políticas. (Luque, 2004, p. 20)

De igual manera, se pueden determinar las similitudes entre las 4P del marketing comercial y el marketing político:

El producto: para el marketing comercial, este es definido como "algo que puede ser ofrecido en un mercado para satisfacer un deseo o una necesidad" (Kotler 2002, p. 442). El producto en el marketing político lo componen tres ejes fundamentales, de acuerdo con Orosa (2009): "la ideología y el programa, el partido político y el candidato", los cuales se combinan para conformar la oferta que ha de presentarse al electorado y que se puede denominar concepto político. Es así como el producto, en el caso del marketing político, es un concepto en el que confluyen la ideología y programa, el partido político y el candidato. Este último es quien debe realizar la "venta" de su 
programa e ideología del partido al cual pertenece y quien debe, con sus propuestas, satisfacer las necesidades de sus clientes, que en este caso son sus votantes.

El precio: cuando se habla de precio se hace relación al valor que debe pagar el consumidor para adquirir un producto. En un proceso electoral, el precio es lo que le cuesta a un votante elegir una opción, optar por un candidato y darle su voto. Cuando se elige un candidato se paga un precio en el tiempo utilizado para el estudio de las propuestas, se paga un precio por sacrificar otras opciones que pueden probablemente satisfacer las expectativas y se paga un precio al asumir la responsabilidad de haber elegido bien o mal.

La plaza o distribución: en términos de marketing comercial, hace referencia a los sitios donde se distribuye el producto y a todos los canales disponibles para el público en los que puede adquirir el producto. En el caso del marketing político, hace alusión a los lugares donde el candidato manifiesta sus ideas y propuestas a los ciudadanos a través de discursos o eventos que permiten identificarlo y diferenciarlo de otras propuestas y evaluar sus ideas.

La promoción: tanto para marketing político como para marketing comercial, la promoción permite dar a conocer las estrategias de venta del producto y los medios por los cuales se va publicitar para el conocimiento por parte del público. En el caso del marketing político, son las estrategias de comunicación para informar al público sobre los programas y proyectar la imagen del candidato. La promoción en el marketing comercial contiene varias herramientas, como las relaciones públicas, el marketing directo y la publicidad, entre otras. 
Figura 1. Las $4 \mathrm{P}$ aplicadas al marketing político

\section{LAS 4P DEL MARKETING POLÍTICO}

\begin{tabular}{|c|c|c|c|}
\hline PRODUCTO & PRECIO & PLAZA & PROMOCIÓN \\
\hline $\begin{array}{l}\text { Concepto } \\
\text { político } \\
\text { Ideología y } \\
\text { programa } \\
\text { partido } \\
\text { político } \\
\text { candidato } \\
\text { Orosa (2009). }\end{array}$ & $\begin{array}{l}\text { Voto que } \\
\text { deposita el } \\
\text { ciudadano } \\
\text { a cambio de } \\
\text { beneficios; } \\
\text { costos en que } \\
\text { incurre con su } \\
\text { elección al no } \\
\text { votar por otro } \\
\text { candidato. }\end{array}$ & $\begin{array}{l}\text { Lugares donde } \\
\text { el candidato } \\
\text { proyecta } \\
\text { su imagen, } \\
\text { manifiesta } \\
\text { sus ideas y } \\
\text { propuestas a } \\
\text { los ciudadanos } \\
\text { a través de } \\
\text { discurso o } \\
\text { eventos y } \\
\text { donde actua en } \\
\text { su nombre el } \\
\text { voluntariado. }\end{array}$ & $\begin{array}{l}\text { Estrategias de } \\
\text { comunicación } \\
\text { para informar } \\
\text { al público sobre } \\
\text { propuestas } \\
\text { y exponer la } \\
\text { imagen del } \\
\text { candidato. }\end{array}$ \\
\hline
\end{tabular}

Fuente: elaboración propia.

\section{El plan de marketing}

El plan de marketing es un documento escrito (para que pueda ser consultado por los miembros del equipo) donde se detalla lo que se espera conseguir en una actividad comercial, el presupuesto y tiempo a invertir, la descripción de las acciones que han de ejecutarse para cumplir con los fines propuestos y los mecanismos de control que permitan detectar desviaciones del objetivo.

El plan de marketing político, como lo define Barranco citado por Orosa (2009):

Es el proceso mediante el cual un partido determina sus objetivos y oportunidades de captación de votos, asigna sus 
recursos humanos y económicos en función de dichos objetivos y establece el sistema adecuado de control del mismo". (Barranco Saiz, 2003, p. 65)

Aunque existen diferentes modelos del plan de marketing, se pueden destacar los siguientes elementos:

Investigación: en primera instancia, el desarrollo del plan de marketing se basa en el conocimiento del consumidor, por lo que el punto de partida es la investigación. Es fundamental para todo el proceso conocer los sentimientos, necesidades, hábitos y motivaciones profundas que motivan a las personas a elegir determinadas opciones dentro de varias alternativas, así como los factores externos que pueden influir en la toma de sus decisiones y en la forma como pueden percibir las ofertas disponibles.

La investigación también se dirige al entorno económico, social, político, cultural; a la opinión pública; a cómo se perfila la competencia, es decir las demás opciones políticas, candidatos, programas, estrategias de comunicación; a las características e influencia de los medios de comunicación y su impacto en el electorado. En otras palabras, contar con información actualizada de todos los factores que de una u otra manera influirán en el proceso electoral.

Diagnóstico: a partir de la información se elabora un diagnóstico que puede organizarse a través de matrices propuestas por las teorías de estrategia empresarial. Una de las más conocidas es el DOFA, instrumento de análisis que permite describir el estado de una organización, examinando las debilidades, oportunidades, fortalezas y amenazas en un momento dado.

Otra de las herramientas utilizada en investigación de mercados es el mapa perceptual que permite, entre otros aspectos, visualizar cuál es el posicionamiento de un factor (bien, servicio, empresa, candidato) en el mercado, cuáles son las ideas y valores que el público asocia al ente investigado, en qué posición se encuentra la competencia con respecto a los ideales del público objetivo y cuáles de estos ideales o deseos están desatendidos. 
Figura 2. Ejemplo de mapa perceptual

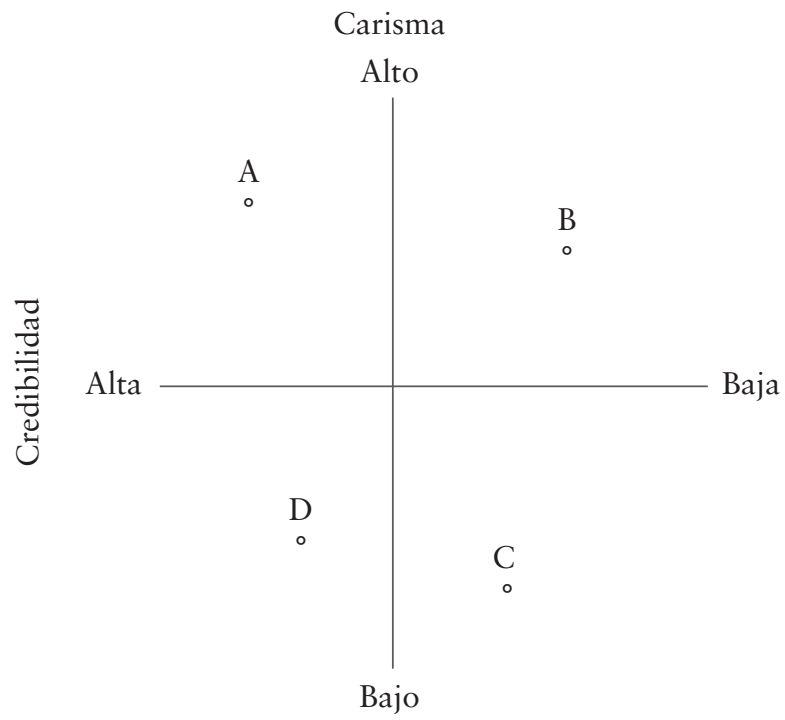

Fuente: elaboración propia.

Segmentación: uno de los procesos que aporta el marketing es la segmentación. Este consiste en dividir a la población en grupos de acuerdo a característica comunes que puedan influir en la forma como toman sus decisiones de compra o de voto. Un candidato, por la naturaleza de su objetivo, debe dirigirse a casi la totalidad de la población, por lo que es aún más necesario definir las características de los diferentes grupos a los que va a dirigir sus mensajes y programas.

Existen los grupos de población en el núcleo familiar: amas de casas, estudiantes, empleados; gremios que agrupan y defienden intereses de diversos sectores: educativo, construcción, comerciantes; grupos con diferente ubicación geográfica: norte, sur, ciudad o campo, y personas que votan siempre, ocasionalmente o nunca.

El candidato debe tener un panorama claro de la situación actual de todos los segmentos: dónde tiene mayor fortaleza y mayor visibilidad para concentrar sus esfuerzos en posicionarse con propuestas que satisfagan necesidades específicas. 
Objetivos: con un panorama claro de la situación del mercado y definido el público objetivo — detallando las características de los segmentos de población- se enfocarán los esfuerzos en concretar los objetivos que se quieren lograr con la implantación del plan de marketing, esto significa tener claro en dónde está y a dónde quiere llegar.

En este contexto, es necesario diferenciar entre los objetivos políticos y los objetivos electorales: los primeros se definen en términos de la ciudad, región o país que el partido y candidato quieren ver en un futuro y los segundos, en función de los resultados que se quieren obtener en las urnas: en qué regiones del país se quiere ganar, votos que se esperan obtener, etc.

Hay varios objetivos por puntualizar y tienen que estar alineados en toda la planeación. Es así como se definen los objetivos de marketing y, a partir de estos, los objetivos de comunicación y, congruentemente, los objetivos de publicidad. Así mismo, para cada uno de los elementos del mix de marketing se han de trazar objetivos, es decir: qué se quiere lograr con el producto o concepto político; qué se quiere alcanzar en términos de precio o votos; qué resultados se desean obtener con las estrategias implementadas en los diferentes canales de distribución de la propuesta política y de la imagen del candidato qué se aspira conseguir y con las diferentes actividades de promoción o comunicación.

Estrategias: a partir de los objetivos que se pretenden alcanzar, se definen estrategias para cada uno de ellos. Las estrategias de marketing se refieren a "las líneas maestras que hay que seguir para alcanzar los objetivos propuestos” (Hernández, Olmo, y García, 2000, p. 33).

La estrategia requiere de creatividad y es la que permite diferenciarnos de la competencia. Aira (2015) la define como “el diseño armónico y coherente de toda nuestra acción presente y futura, es la estructura que sustenta y armoniza nuestras actuaciones para llegar con más posibilidades de éxito a nuestro objetivo" (p. 17). A cada factor de las 4 $\mathrm{P}$ del mix de marketing se le definen unos objetivos y de acuerdo con ellos se trazan las estrategias.

Las estrategias de marketing tienen que ver con la ampliación de cuota de mercado, la diferenciación de la competencia o atraer segmentos de población específico y las estrategias de producto, que en 
el caso del marketing político se enfocan en generar herramientas que permitan dar credibilidad a las propuestas presentadas a la población y de generar confianza entre los electores.

Ejecución: en el plan de marketing se elabora un plan de acción, este se registra en una matriz donde se detallan las estrategias para cada objetivo y se precisan las tácticas que se van a llevar a cabo para desarrollar dichas estrategias. Así mismo, se asignan los responsables de cada tarea y se especifican los tiempos de ejecución, además de designar el presupuesto necesario para cada acción.

Para el marketing político es importante contar con un equipo de trabajo que permita asignar roles durante la campaña, es decir: un gerente de campaña, un líder en comunicaciones, un grupo de logística, un equipo de presupuesto, etc.

Control: según Orosa, "todo control se basa en la obtención de la denominada 'desviación' que puede definirse como la diferencia entre lo que se había previsto y las realizaciones que se van consiguiendo" (Orosa, 2009, p. 71).

En los periodos electorales es común hacer un seguimiento exhaustivo de los resultados mediante las encuestas de opinión contratadas por los partidos o los medios de comunicación. Estas reflejan las tendencias de la población hacia una u otra propuesta, lo que conlleva a que los candidatos y sus partidos ajusten sus estrategias para atraer efectivamente a los electores. Hoy en día, con las posibilidades que ofrece Internet y las redes sociales, este pulso es más fácil de medir y la interacción en tiempo real permite una inmediata retroalimentación de la aceptación o no de la imagen, ideas y programas de un candidato. Además, toda la información que se obtiene con la evaluación de los resultados servirá para futuras campañas. 
Figura 3. Estructura del plan de marketing político/electoral

\section{Plan de Marketing Político-Electoral}

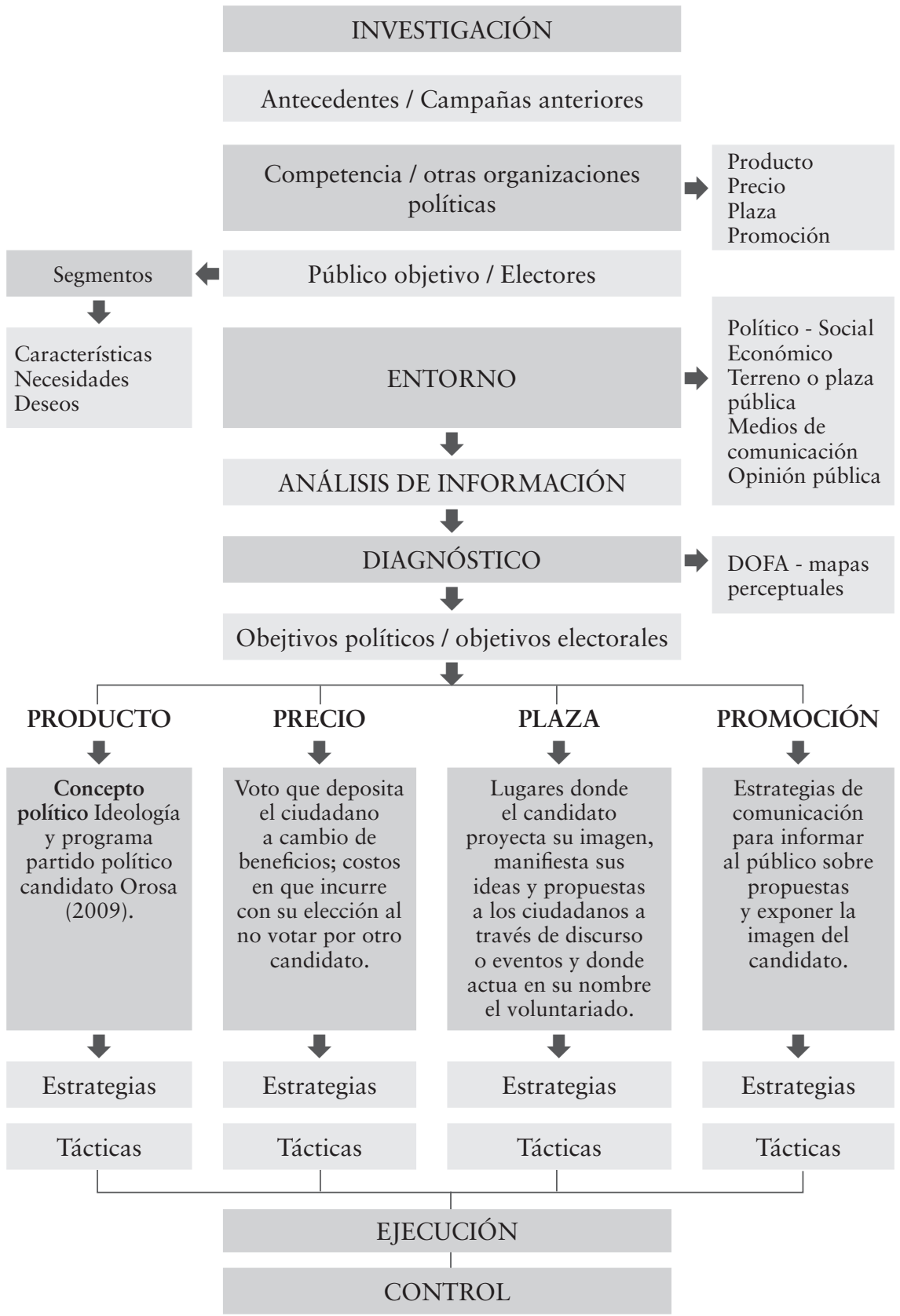

Fuente: elaboración propia. 


\section{Investigación de mercados}

Toda campaña política —y específicamente la electoral— debe estar sustentada en un proceso de investigación que proporcione información acerca de las características y situación actual de los principales actores del mercado y que refleje los intereses de los electores. La investigación de mercados se define como la técnica que recopila información de un tema que se desea conocer para, posteriormente, clasificar e interpretar la información obtenida. Esta información es la base para tomar decisiones y diseñar estrategias con mayor probabilidad de éxito.

Los ciudadanos son la base de la investigación política y es necesario conocer las percepciones y el posicionamiento que tienen de los partidos y candidatos, pero también, "el nivel de satisfacción y carencias, en definitiva, saber qué demandan, que reivindican y qué quieren" (Asencio, 2010, p.186).

Para una mejor definición de programas, estrategias y de los mensajes de la comunicación política, es necesario identificar segmentos de población, esto significa grupos homogéneos de población con características y necesidades similares. Más adelante, en el apartado que corresponde a la elaboración de las propuestas y el mensaje, se exponen los elementos correspondientes para tener en cuenta.

\section{Fuentes de información en marketing político}

De acuerdo con el origen de las fuentes de información, estas se clasifican en primarias y secundarias. Estos dos tipos de fuentes pueden a su vez ser internas o externas. Internas cuando están disponibles dentro de la organización y externas cuando lo están en otras entidades. 
Figura 4. Fuentes de información en marketing

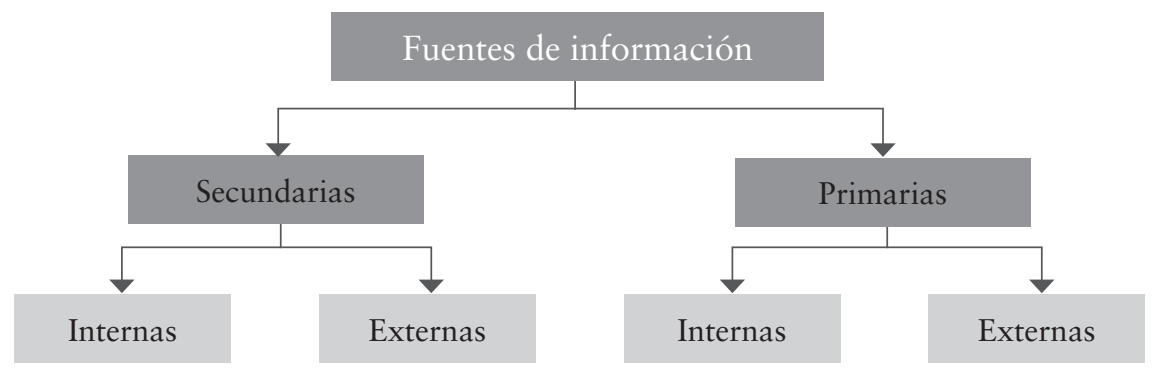

Fuente: elaboración propia.

Fuentes de información primaria: son las que proporcionan información directa del público sujeto de la investigación. Esta se recopila a través de encuestas y otros métodos de indagación cualitativa como entrevistas, observación directa o grupos focales y es información original que se obtiene por primera vez.

Fuentes de información secundaria: es la información que se obtiene de documentación disponible, datos ya existentes, virtuales o físicos. Ejemplos de este tipo de fuentes son los resultados de investigaciones previas y cifras de las que se dispone al interior de una organización.

En el ámbito político se dispone de estudios, sondeos de opinión, noticias de prensa, estudios de organizaciones gremiales o resultados de elecciones anteriores. De acuerdo con Maarek (citado en Orosa, 2009), los resultados de elecciones anteriores, a pesar de suministrar información real del comportamiento de los votantes, tienen inconvenientes como la distancia en el tiempo de una a otra votación y la mayoría de las veces el cambio de candidatos; sin embargo, proporcionan información que se debe analizar ponderando las respectivas diferencias, indagando las estrategias, la focalización, la publicidad, las propuestas, los perfiles del equipo de trabajo que estuvo presente en la campaña y el presupuesto utilizado. Es necesario agotar la consulta de fuentes secundarias antes de decidir recopilar información primaria, por el tiempo, conocimiento y gastos que conlleva una investigación; en algunos casos la consulta de fuentes secundarias es suficiente para analizar los datos disponibles tanto interna como externamente y plantear un panorama general del entorno. 


\section{El proceso de la investigación de mercados}

Luque (2004) define cuatro pasos para una propuesta investigación de mercados:

- Objetivos de la investigación: problemas a estudiar, objetivos, información a suministrar, utilización del estudio.

- Especificación de las técnicas del estudio: características del muestreo y del cuestionario, forma de recogida de la información, requisitos del análisis y la preparación del informe, calendario, etc.

- Estimación del coste: qué se incluye en el presupuesto y qué no, formas de pago.

- Otros temas de tipo contractual: exclusividad, publicación de los datos, cláusulas, penalizaciones, etc.

Por su parte, Prieto (2009) sugiere el siguiente esquema para la organización de un proyecto de investigación de mercados:

- Título

- Antecedentes

- Objetivos

- Metodología

- Muestra

- Cronograma de actividades

- Presupuesto

- Administración del proyecto

- Resultados esperados

- Conclusiones y recomendaciones

- Tablas

- Figuras

- Anexos especiales 
Cuando se ha decidido que existe la necesidad de una investigación de mercado y se ha delimitado claramente el problema a resolver, procedemos a definir los aspectos del proceso de investigación, el cual podemos resumir en el siguiente esquema:

Figura 5. Proceso de la investigación de mercados

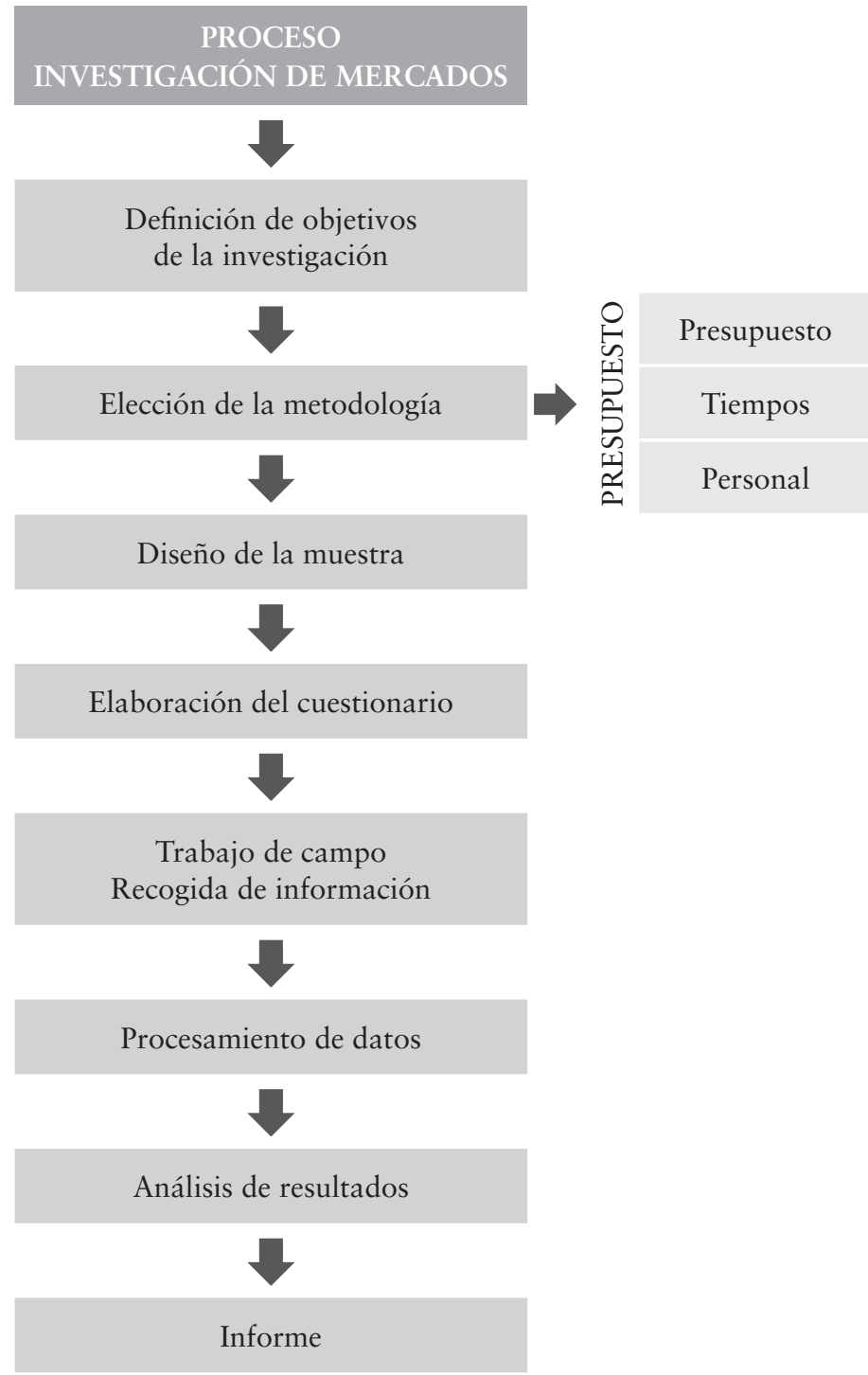

Fuente: elaboración propia. 


\section{La elaboración del cuestionario}

El cuestionario o encuesta es el instrumento a través del cual se recoge la información en una investigación y debe estar diseñado de tal manera que facilite las respuestas al entrevistado y no induzca las respuestas o sesgue la información. Igualmente, se debe tener en cuenta la técnica que se va a utilizar: es diferente el diseño de una encuesta que va a ser enviada por correo o se va a hacer telefónicamente a una encuesta cara a cara, las primeras necesitan más sencillez y brevedad mientras que la última posibilita mayor extensión. Las características de la muestra también condicionan el tipo de preguntas; además, las técnicas de análisis de datos condicionan las escalas de medida utilizadas. (López y López, 2005).

Tipos de pregunta: existen tres tipos de preguntas en función de la libertad que se da para las respuestas: 1) preguntas abiertas, que dan la posibilidad de recoger la opinión tal como la expresa el entrevistado; 2) cerradas, en las cuales el entrevistado tiene que escoger entre las opciones de respuesta registradas en el cuestionario, o 3) mixtas, cuando se dan opciones de respuesta y además se incluye un espacio para una respuesta abierta que complemente o explique las anteriores (López y López, 2005).

Unas y otras tienen ventajas y desventajas: mientras las preguntas cerradas facilitan las respuestas, agilizan la encuesta y son más fáciles de codificar y analizar, son rígidas en la información que suministran, tienen mayor riesgo de error en la elección de la respuesta y coartan las opiniones de los encuestados. Las abiertas, por su parte, proporcionan mayor información e inclusive nuevas ideas, pero exigen mayor esfuerzo y tiempo para ser respondidas y dificultan su tabulación y análisis.

Hay también preguntas filtro y de control: las primeras permiten seleccionar a los ciudadanos que interesa entrevistar. Por ejemplo, en una encuesta electoral una pregunta filtro puede ser “¿piensa votar en 
las próximas elecciones?", si la respuesta es NO, se puede dar por terminada la encuesta si el objetivo de la investigación es medir la intención de voto por los diferentes candidatos o pasar a otra pregunta si se necesita otro tipo de información. Las preguntas de control tienen como finalidad comprobar la veracidad de las respuestas anteriormente proporcionadas por el encuestado.

Los cuestionarios, antes de ser aplicados a toda la muestra, se deben probar en un grupo pequeño con el fin de corregir posibles incoherencias, preguntas con sesgos o problemas de redacción.

\section{Diseño de la muestra}

De acuerdo con Orosa, "en el diseño de la muestra se deben considerar dos aspectos: la determinación del volumen de la misma y su consiguiente error muestral, así como la elección del tipo de muestra” (Orosa, 2009, p. 149). El error muestral hace referencia al grado de inexactitud que se comete al analizar solo una muestra y no toda la población. Por consiguiente, a mayor volumen, menor error, pero mayor costo de la investigación.

Existen varios métodos de muestreo, que, como lo comentan López y López (2012), se pueden dividir en dos grandes bloques: los muestreos probabilísticos y los no probabilísticos. Los muestreos probabilísticos son aquellos en los que cada uno de los individuos de la población objeto de estudio tiene las misma probabilidad de ser elegido para conformar la muestra. Este método genera mayor representatividad de la población, esto quiere decir que los resultados pueden ser generalizados a toda la población. En los no probabilísticos, la muestra es elegida de acuerdo con los criterios que determina el investigador, es más fácil de diseñar y los costos son menores.

\section{La investigación cuantitativa y cualitativa}

Existen dos métodos de recopilación de información primaria: la investigación cuantitativa y la investigación cualitativa. 


\section{Investigación cuantitativa}

Es un conjunto de técnicas que permite recoger información a una muestra representativa de una población previamente establecida, a través de un cuestionario o encuesta y en donde la opinión de cada encuestado puede ser extrapolada a un grupo de la población, es decir, lo que opina un individuo de la muestra puede corresponder a la opinión de un grupo de la población tomada como universo. Las respuestas normalmente se organizan en tablas - lo que conocemos como tabularpara posteriormente medir, contar, comparar la información y analizar los resultados de las diferentes combinaciones de datos.

Las encuestas de opinión o sondeos son consideradas como "la principal fuente de información y medida de la opinión” (Orosa, 2009). Presentan inconvenientes como su elevado costo y un alto grado de error. Los resultados de las encuestas de opinión también generan modificaciones en la intención de voto de los electores, bien sea para otorgar su voto al candidato que en las encuestas va perdiendo o, por el contrario, conceder el voto al candidato que va ganando para formar parte de la mayoría (Orosa, 2009).

No todas las campañas necesitan encuestas, depende de la magnitud de estas y de cómo el candidato quiera que le aporte a sus propuestas, ya que en ocasiones estos conocen el territorio o son líderes que llevan tiempo viviendo allí, por lo que tienen identificadas las necesidades.

Entre las técnicas cuantitativas más utilizadas en el campo de la investigación política, destacan las siguientes (Luque, 2004):

- Entrevista por correo: se envía un cuestionario con una carta explicativa a los integrantes de la muestra. El cuestionario debe ser claro y sencillo de responder, ya que el entrevistado no puede resolver dudas y una vez diligenciado debe devolverlo por correo. Tiene como dificultad el bajo índice de respuesta.

- Entrevista telefónica: la entrevista se realiza por teléfono a una muestra previamente diseñada. Tiene un problema fundamental y es el rechazo, pero si es superado, constituye una valiosa herramienta para obtener información de intención de voto, valoración de líderes u organizaciones políticas. 
- Entrevista personal: se recoge la información a través de un cuestionario y en entrevistas cara a cara con el ciudadano. Tiene ventajas como la posibilidad de aclarar dudas y mayor porcentaje de respuestas, aunque el tiempo y las logísticas necesarias son los principales inconvenientes.

- Encuesta ómnibus: se refiere a insertar una batería de preguntas políticas o electorales en un cuestionario que mide otros temas. El costo se reduce, pero los resultados no son tan confiables por la confusión que pueden causar en el encuestado los diferentes temas; además, hay que asegurarse de que el público de una encuesta tan general se adecue a los objetivos específicos de la investigación electoral.

- A esta clasificación podemos añadir la encuesta vía Internet, que ofrece ventajas como la rápida respuesta y tabulación de los datos, pero se debe tener en cuenta que no es fácil cubrir todos los segmentos de población debido a la todavía deficiente penetración de Internet y porque algunos segmentos sencillamente no lo utilizan, como los adultos mayores.

\section{Investigación cualitativa}

Es una metodología para la obtención de información a través de técnicas que permiten respuestas abiertas de muestras pequeñas de población. En estas se manifiestan sus motivaciones, actitudes, hábitos y sentimientos con respecto al problema planteado. En la recolección se utilizan enfoques intuitivos e interpretativos que no pretenden suministrar datos estadísticos o científicos. Además, se trata de explorar y comprender los fenómenos mediante la observación y el análisis de las respuestas de las personas involucradas en el objeto de estudio.

De acuerdo con Luque (2004), las técnicas cualitativas más utilizadas en el ámbito político son:

- Entrevista en profundidad: en la cual un entrevistador, a través de un cuestionario o guion no estructurado, pregunta al entrevistado dejando que exprese libremente sus motivaciones, 
actitudes y opiniones con todo el detalle posible acerca del fenómeno de estudio.

- Sesiones de grupo: en el que un moderador dirige una discusión de un grupo de personas, propiciando el debate y la interacción para que expresen sus opiniones y diferentes puntos de vista.

- Esta técnica exige que se creen varios grupos correspondientes a diferentes segmentos para contrastar los resultados. Para un candidato a Edil, por ejemplo, puede ser conveniente saber qué opinan y cuáles son las necesidades específicas de las amas de casa, los comerciantes o estudiantes universitarios de su localidad, por lo que se podrán realizar sesiones con grupos homogéneos de ocho o diez personas de cada uno de estos segmentos.

- Técnicas proyectivas: se agrupan una variedad de técnicas como la interpretación de dibujos, desempeño de papeles, asociación de palabras y terminación de frases.

- Técnicas basadas en la observación: registra las reacciones o comportamientos de los individuos, puede ser en actos públicos, mesas redondas, visitas a establecimientos o debates en los que participa el candidato. De manera científica se registran las reacciones, como cambios en la tensión arterial, diámetro de la pupila o el pulso.

La observación también puede realizarse sistemáticamente a través de la simple contemplación del comportamiento humano ante determinados hechos. Las ventajas de este método son:

- Que hace posible obtener la información del comportamiento tal y como ocurre;

- Es independiente de la capacidad y del deseo de un sujeto para informar sobre sí mismo;

- Solicita menos cooperación activa por parte de los sujetos observados que la entrevista, encuesta o experimento; además, algunas dificultades que se dan en otros métodos de investigación como la no respuesta, la falta de sinceridad, el querer dar una respuesta aceptada socialmente (Ruiz, 2012, p. 76). 
La Figura 6 muestra los pasos y tipos de investigación de mercados.

Figura 6. Fuentes de información en la investigación de mercados

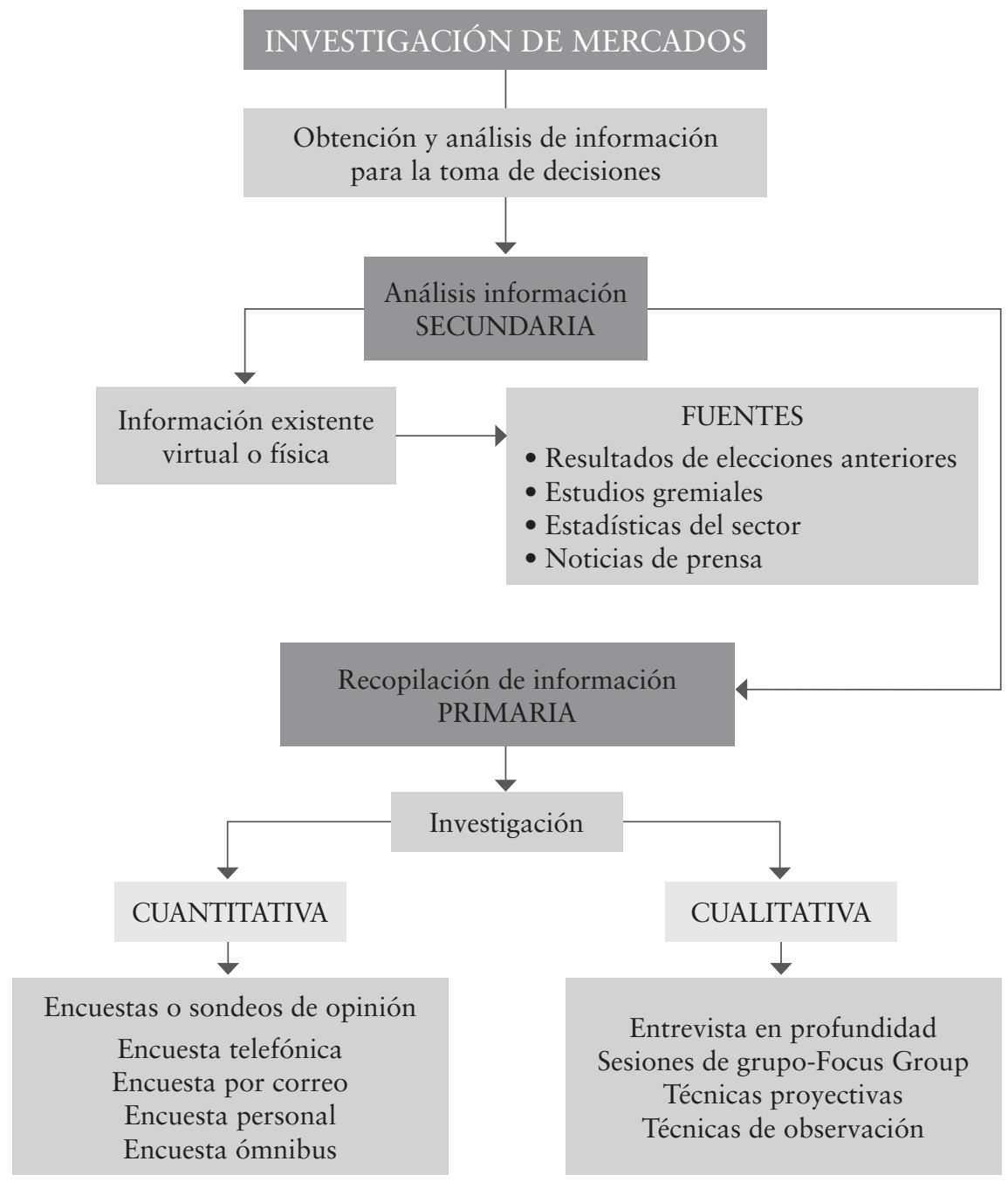

Fuente: elaboración propia. 
El análisis de datos cuantitativo puede iniciarse desde un modelo elaborado de estudios anteriores o basado en un marco teórico previo que se usa como "hipótesis de trabajo". Con el análisis se busca comprender los ejes que orientan el comportamiento, para formular generalizaciones aplicables tan solo a contextos similares (análisis inductivo).

Los pasos son:

- Transcripción textual de los datos: constituye la unidad de análisis principal. Tanto para las entrevistas en profundidad como para las sesiones de grupo y demás técnicas cualitativas se hace la transcripción digital textual de la información, esto permite revisar la información detalladamente y también facilita su codificación.

- Reducción de datos o codificación: consiste en dividir la información en unidades de análisis más pequeñas, identificando y diferenciando unidades de significado y eliminando la información inservible. Se pueden definir categorías y bajo cada una de ellas agrupar información aportada que tenga que ver con cada clasificación.

- Disposición y transformación de datos: donde se seleccionan aquellos grupos de categorías más relevantes para dar respuesta a las principales preguntas del estudio. En esta fase se lleva a cabo el análisis descriptivo de los datos, el cual se puede lograr a través de listas de conteo (clasificaciones detalladas), redes causales o conceptuales, matrices descriptivas e inclusive gráficos estadísticos.

- Hacer los análisis de validez interna de la información: lo cual hace referencia al grado de coherencia lógica interna de los resultados y a la ausencia de contraindicaciones con resultados.

\section{Validez de los datos}

- Verificar la representatividad: examinar cuidadosamente los hallazgos que reflejen situaciones atípicas. 
- Revisar los efectos del investigador: analizar si su presencia generó ansiedad o tensión entre los participantes.

- Triangulación: para medir la consistencia de los datos. Esto se puede hacer comparando datos cualitativos y cuantitativos, contrastando información de diferentes informantes y/o comparando información de diferentes observadores.

\section{Campaña de publicidad política}

Una de las herramientas más poderosas del marketing es la publicidad, pero esta es apenas una de las actividades que conforman las comunicaciones integradas de marketing (CIM), por lo tanto, los mensajes publicitarios deben estar articulados con las demás acciones de comunicación que se realicen dentro de una campaña política o electoral, para lograr un mensaje coherente.

\section{Comunicaciones integradas de marketing (CIM)}

Se refieren al uso estratégico coordinado de la promoción para crear un mensaje consistente a través de múltiples canales con el fin de asegurar un impacto positivo en el público. Las CIM toman un punto de vista de 360 grados, pues considera todos y cada uno de los contactos que, en el caso del marketing político, tiene un ciudadano en su relación con un partido político o en el caso del marketing electoral, con el candidato.

La clave de las CIM es la consistencia y la uniformidad del mensaje a través de todos los elementos con los que se comunica el candidato, en sus apariciones públicas, en los debates o a través de la publicidad.

Hay que diferenciar el plan de CIM del plan de publicidad, el cual es solamente una parte de las comunicaciones de la empresa. Al respecto Ferré y Ferré comentan:

"¡La comunicación es un concepto amplio! ¡La publicidad es sólo un medio de comunicar...!” (1996, p. 1). 


\section{La publicidad en el mix de marketing}

La publicidad hace parte de las actividades de marketing, enfocada a la promoción de un bien, una idea, una organización o un personaje. Cuando un partido político se enfrenta a unas elecciones, con la representación de un candidato que ha definido su imagen de acuerdo con sus propias características y las de su electorado, y ha definido un programa que da respuesta a las necesidades de una comunidad, es tiempo de comunicarse con esta y presentar de manera clara sus propuestas, resaltando lo que lo diferencia de sus competidores.

Dentro de las actividades de promoción tenemos muchas herramientas que nos ayudan a comunicarnos con el público y tradicionalmente se han dividido en dos tipos de actividades: Above the Line (ATL) y actividades Below the Line (BTL):

ATL es la publicidad pagada y transmitida a través de los medios masivos de comunicación como prensa, radio, televisión e Internet. Es la forma de publicidad más convencional, es impersonal y masiva.

BTL emplea medios alternativos, tales como correo directo, correo electrónico, telemercadeo, venta personal, patrocinios, merchandising, relaciones públicas, promociones, etc. La intención del BTL es llegar con mensajes personalizados con el objetivo de crear una relación directa con el receptor del mensaje, algo que no se logra a través de los medios tradicionales.

\section{¿Qué es la publicidad?}

La publicidad es considerada como una de las más poderosas herramientas del marketing, específicamente de la promoción.

Según AMA (American Marketing Asociation), la publicidad consiste en

la colocación de avisos y mensajes persuasivos, en tiempo o espacio, comprado en cualesquiera de los medios de comunicación por empresas lucrativas, organizaciones no lucrativas, 
agencias del estado y los individuos que intentan informar y/o persuadir a los miembros de un mercado meta en particular o a audiencias acerca de sus productos, servicios, organizaciones o ideas. (Puon, 2013)

De esta manera, la publicidad tiene características que la diferencian de las otras herramientas de promoción: es masiva e impersonal, debido a que se difunde a través de los medios masivos de comunicación, esto dificulta medir su impacto, pues no se obtiene una retroalimentación rápida; es paga y el mensaje es controlado, es decir, el anunciante decide qué transmitir, de qué forma y a través de qué medios.

\section{Reglas de la comunicación política}

\section{El mensaje es el eje de la comunicación política y de la publicidad}

Maarek (2009) define cuatro reglas que se aplican de forma sistemática a cualquier etapa del proceso de comunicación:

- Coherencia: ninguna decisión de campaña se toma sin contrastarla con las restantes, con campañas anteriores o con las de otros políticos del partido.

- Replanteamiento sistemático de campañas anteriores: prohíbe reproducir una campaña precedente (nuevos candidatos o nuevos acontecimientos hacen replantear la campaña).

- Desmarque mínimo: resaltar una ventaja, como mínimo, en un aspecto concreto del político que lo desmarque de sus competidores (defectos o cualidades).

- Máxima seguridad: no poner en práctica una estrategia de comunicación que entrañe un riesgo para el político. 


\section{Definición de la imagen del político}

La imagen es la idea que se forma en la mente sobre determinado objeto o individuo por la información que se recibe de este. Todas las personas proyectan una imagen a través de la transmisión de estímulos verbales y no verbales y están expuestas a ser percibidas por los otros de forma positiva o negativa, dependiendo de la clase de mensajes que transmiten y de cómo los reciben los receptores. La construcción de la imagen de un personaje político requiere de un proceso racional y estratégico, combinando estímulos que interesen y agraden al público y en los cuales las características propias del candidato se respeten para lograr mayor credibilidad, pero también conociendo cómo el público al que se quiere abordar decodifica los mensajes para que el mensaje recibido se acerque lo más posible al mensaje transmitido. El objetivo es lograr construir una buena imagen teniendo en cuenta que, a mejor imagen, mayor es el poder de influencia en el público al que se dirige la campaña.

De acuerdo con Maarek (2009), la construcción de la imagen del político se realiza bajo tres principios:

- Subjetivo: la imagen se construye tanto en la emisión como en la recepción, pues no siempre la imagen que se quiere transmitir es la que decodifica el receptor; además, depende de muchos factores que los receptores entiendan y reciban claramente el mensaje. Entre mayor coincidencia se logre entre la imagen proyectada y la imagen percibida, más efectiva es la comunicación.

- Lento: superar el umbral mínimo de notoriedad para percibir la imagen y asociar con ideas y personalidad. Se debe encontrar una idea que sea diferente y que realmente logre superar este umbral, que logre sobresalir de los demás mensajes con los que son bombardeados los posibles votantes.

- Complejo: carácter subjetivo de la recepción. La imagen elaborada para el político debe coincidir con personalidad, pues no se puede construir una imagen de la nada, debe basarse en las características reales del candidato y lograr que el mensaje 
y la personalidad comunicada a través de los diferentes momentos de contacto con el público sea coherente.

\section{La campaña de publicidad política}

Una campaña publicitaria es el periodo de tiempo en el que se hace uso de un determinado tipo de publicidad. Las campañas son realizadas por las agencias de publicidad, empresas especializadas en la elaboración de estrategias, diseño de plataformas creativas y los mensajes publicitarios. Se encargan igualmente de la producción de las piezas publicitarias, esto es spots para televisión, cuñas de radio y desarrollos gráficos para anuncios en prensa, revistas, vallas e Internet.

En las campañas a edilato tal vez no se disponga de presupuesto para la contratación de agencias de publicidad, producción de televisión u otros medios — que además sería un desperdicio por el carácter local que tienen estas campañas-, sin embargo se desarrollará la teoría general con las recomendaciones adaptadas a la situación real de un candidato a edil.

Las agencias inician su trabajo a partir de un documento que el anunciante, en este caso el partido o el candidato, elaboran y entregan a la agencia llamado brief publicitario.

Una vez se ha determinado la imagen del político y los objetivos que se quieren alcanzar con la campaña, se suministra a la agencia de publicidad toda la información que esta pueda necesitar para hacer su trabajo. El documento en el que se recoge esta información se conoce con el nombre de brief. Un candidato a edil y su equipo pueden elaborar su propio brief para contar con un documento organizado que les permita iniciar la estrategia de comunicación y publicitaria.

Los principales puntos de este documento o guía para la realización de una campaña publicitaria son:

- Quién es el candidato: se explica a la agencia su trayectoria, rasgos de personalidad, logros, puntos débiles, etc.

- Características de sus posibles electores: Cuáles son las necesidades, costumbres, motivaciones y hábitos. 
- Análisis del contexto y del terreno: cuáles son las principales problemáticas y características de la región.

- Análisis de la competencia: información de la que se disponga sobre características de los otros candidatos y sus propuestas de campaña.

- Objetivos de comunicación: qué se quiere lograr con la campaña publicitaria.

- Respuesta esperada: qué se espera que haga el electorado al finalizar la campaña — que vote por el candidato, entienda sus propuestas o cambie la imagen negativa que tiene del candidato-.

- Promesa básica o Unique Selling Proposition (USP): cuál es la característica del candidato o de su programa que se quiere destacar y que lo va a diferenciar de los demás candidatos.

- Presupuesto: se debe informar a la agencia cuál es el presupuesto asignado para la elaboración de la campaña, producción de piezas publicitarias y compra de los espacios publicitarios en los medios de comunicación.

- Tiempos de la campaña: se establecen fechas para entregas de avances de la campaña por parte de la agencia para evaluación y aprobación. Se define la fecha de lanzamiento de la campaña.

\section{Estructura de la campaña de publicidad}

Una vez la agencia tiene el brief, se socializa con el equipo que se va a ocupar de la campaña y, si es necesario, se presenta al anunciante un contra-brief, en el que la agencia adiciona o corrige aspectos que se hacen necesarios para el buen desarrollo de la campaña y para el cumplimiento de los objetivos. Una vez ha sido aprobado el brief, la agencia inicia su trabajo.

Los pasos a seguir para estructurar una campaña publicitaria son los siguientes:

- Definir objetivos publicitarios.

- Identificar a quienes se va a dirigir la publicidad.

- Asignar un presupuesto. 
- Estrategia creativa y determinación del eje de la campaña.

- Redactar el mensaje publicitario.

- Definir medios o canales publicitarios.

- Producción de piezas publicitarias.

- Lanzamiento y control de la campaña publicitaria.

\section{Definir objetivos publicitarios}

Con base en la información aportada por el anunciante en el brief, se establecen los objetivos de la campaña publicitaria, es decir, se señala qué se quiere lograr con ella. Los objetivos publicitarios de la campaña política pueden resumirse en:

- Informar sobre las propuestas, ideología o aspectos específicos de la contienda electoral.

- Persuadir a través del manejo de la imagen y mensajes para conseguir una acción, que en el caso electoral es el voto.

- Recordar permanentemente sobre la opción política.

En época de elecciones, el cumplimiento de los tres objetivos es fundamental, los candidatos necesitan informar a los ciudadanos de sus programas y persuadirlos con las herramientas que ofrece la publicidad para convencerlos de que es la mejor opción y para mantener la recordación de su candidatura en la mente de los posibles electores.

\section{Identificar el público o el mercado objetivo}

El público objetivo o target es el conjunto de personas con ciertas características en común al que se dirige una acción publicitaria. En la campaña publicitaria política, el público objetivo son todos aquellos ciudadanos de un área geográfica específica con posibilidad de elegir a sus gobernantes. Deben ser definidos de la forma más explícita posible 
sus hábitos, edades, estilos de vida, cultura, costumbres, niveles de ingreso, roles y necesidades.

\section{Determinación del eje de la campaña}

Es la idea creativa alrededor de la cual va a girar el mensaje publicitario. Debe estar basada en el beneficio básico de la propuesta o ventaja diferencial del candidato. Para hacer la selección del tema de campaña conviene que tengamos en cuenta tres factores:

- Las características del candidato.

- Las necesidades y deseos del público al que va dirigido.

- La publicidad o temas de campaña de la competencia

\section{Redactar el mensaje publicitario}

Los textos utilizados en los mensajes publicitarios deben tener coherencia en todos los medios de comunicación que se van a utilizar y ser adaptados a cada uno de ellos, a sus formatos específicos y a sus diferentes audiencias. En las agencias de publicidad esta labor la realizan los copywriters, profesionales que se especializan en el manejo del lenguaje, crean textos capaces de transmitir con las palabras adecuadas las ideas que se quieren comunicar y producir el efecto deseado.

\section{Definir medios o canales publicitarios}

Una de las partes más importantes del trabajo publicitario es seleccionar los mejores medios de comunicación para hacer llegar el mensaje al público seleccionado. Definir los medios que se van a utilizar - $\mathrm{CO}^{-}$ nocidos como mezcla o mix de medios- es elegir los medios de comunicación conocidos y disponibles por medio de los cuáles se van a transmitir los mensajes publicitarios. Una campaña de publicidad no 
necesariamente debe pautar en todos los medios; por razones de presupuesto y estrategia se deben elegir aquellos que son más afines al público objetivo y que se adapten al presupuesto; además, dependiendo de los hábitos de consumo de medios del público, es importante también elegir y combinar los medios con mayores audiencia en los diferentes momentos del día y la semana.

Una mezcla de medios para campañas de edilato, teniendo en cuenta las limitaciones de presupuesto, puede estar basada en impresos como volantes o piezas en los que en la creatividad y utilidad puede residir su notoriedad; además, se puede hacer uso de buscadores, portales y redes sociales. También se puede recurrir a la radio, pues es un medio mucho más barato que la televisión. De acuerdo con lo anterior, se puede elaborar una selección de medios disponibles y con audiencia dentro de la localidad como periódicos o publicaciones locales, emisoras o televisión comunal.

Para la compra de espacios publicitarios es importante tener referencias para la negociación. El valor y conveniencia de cualquier espacio publicitario tienen que ver con la cantidad y características de la audiencia del medio y la duración — para radio y televisión- o tamaño - para medios impresos, prensa, revistas-, no se incluye Internet, pues tiene formatos especiales de negociación. Un índice que puede guiar el precio apropiado a pagar por un espacio es el costo por mil (CPM), que indica lo que cuesta llegar a mil personas del público con dicha publicación y se establece a través de un cálculo simple:

(Valor del espacio publicitario / Total audiencia del medio) x 1.000

El resultado permite comparar diferentes opciones y escoger entre las que nos brinden menor CPM, ya que este índice relaciona costo y cantidad de personas susceptibles de ser impactadas.

Una vez establecida la mezcla de medios, se elabora el plan de medios, para ello se cuenta con estudios de medios, como el estudio general de medios (EGM); el estudio continuo de audiencia radial (ECAR); los reportes de ComScore Colombia, que proporcionan datos actualizados del comportamiento de los colombianos frente a Internet, y el rating de los programas de televisión medido por IBOPE en Colombia. 
A través de estos estudios sabemos que las personas consumen más radio que televisión en las horas de la mañana; las horas de mayor audiencia de televisión están en la llamada Franja Prime o Triple A, que va de lunes a viernes entre las 7:00 p. m. y las 10:30 p. m.; la prensa se lee en la mañana y un mismo ejemplar es leído en promedio por tres personas, e Internet se consume más desde los hogares y el principal uso es el de redes sociales.

Con esta información, se eligen los espacios y momentos más apropiados en cada medio, asegurando que sean estos los que más probabilidad tengan de ser vistos u oídos por el público objetivo, es decir, los programas que en radio, televisión, periódicos, revistas y sitios de Internet sean vistos, oídos o consultados por personas cuyas características se adapten al público al que queremos llegar. Todas estas decisiones hacen de la planeación de medios una actividad que, dentro de la elaboración de campañas, requiere un tratamiento aparte. Es así como este trabajo lo realizan empresas especializadas, conocidas como agencias, brokers o centrales de medios, las cuales se encargan de la estrategia, planeación y compra de medios publicitarios.

Con el plan de medios que mencionamos para campañas a ediles se deben tener en cuenta también todos estos parámetros, el perfil de las audiencias de cada medio disponible y elegido y el valor del espacio teniendo en cuenta la cantidad de lectores, oyentes o televidentes y se preferirán aquellos medios que ofrezcan un menor CPM. Teniendo en cuenta que son varios los segmentos a los que a través de una campaña se quiere comunicar, el estudio del perfil de audiencia de cada medio es de vital importancia, pues se debe adaptar el mensaje dependiendo de las características de la audiencia. Si es una publicación cuya audiencia es principalmente adultos mayores, se debe hablar directamente con un lenguaje que entiendan y con el cual se identifiquen, pero además se debe ser consistente con el tema o eje de campaña establecido en la estrategia creativa. El eje de campaña se mantiene en todas las comunicaciones, pero se pueden redactar diferentes copy dependiendo de la audiencia de cada medio.

El plan de medios debe de estar basado en un principio fundamental: no existe un medio mejor que otro, sino que su eficacia depende de las circunstancias. No se puede decir que la televisión es el mejor 
medio por su mayor audiencia. Es imprescindible conocer la audiencia de los diferentes medios por segmentos de edad, género, clase social, estilos de vida, etc. para determinar cuáles tienen mayor afinidad con el público al que queremos llegar. En la práctica, toda nuestra campaña publicitaria depende del presupuesto del que dispongamos, por eso en la planeación de medios se busca lograr el mayor impacto posible con los recursos disponibles.

\section{Asignar presupuesto}

Para fijar el presupuesto tendremos que tener en cuenta qué medios son los ideales para alcanzar nuestros objetivos y cuál es su costo, cuál es la difusión publicitaria que perseguimos y cuál es la publicidad que están realizando las otras campañas políticas.

\section{Producción de piezas publicitarias}

Cuando se ha definido la estrategia creativa y se han elegido los medios y programas a través de los cuales se va a transmitir la pauta publicitaria, se inicia el trabajo de producción.

Si en la mezcla de medios se ha elegido televisión, se planea la realización del spot o comercial. Generalmente la agencia de publicidad contrata empresas especializadas en producción. La realización de un comercial incluye temas como el casting, es decir, la selección de los actores que darán vida al story board — formato en el que se detalla la secuencia de un comercial antes de su filmación-; elección de locaciones o set de grabación; equipo técnico; iluminación; sonido; posproducción — relacionada con la finalización en estudio del comercial一.

La producción de cuñas de radio se encarga a estudios, productoras de cuñas o a locutores profesionales independientes, quienes graban la historia o el texto de acuerdo con las indicaciones del guion que reciben de la agencia, incluyendo voces, efectos de sonido y música. 
Los diseñadores gráficos de la agencia de publicidad o independientes se encargan de la elaboración del material para vallas, prensa, revistas o Internet, así como del material impreso -folletos, volantes, stickers - teniendo en cuentas las especificaciones de medida, calidad, modelos de color y formato de cada medio.

\section{Lanzamiento y control de la campaña publicitaria}

Se refiere a preparar el material publicitario — folletos, películas, grabaciones para radio, etc. - y enviar a cada uno de los medios contratados de acuerdo con el plan de medios.

Una vez lanzada la campaña de publicidad, tenemos que establecer dos mecanismos de control: a nivel interno se deben controlar las inserciones y el presupuesto, a nivel externo es necesario controlar los resultados de la campaña ante el consumidor y las posibles reacciones de las campañas de los otros candidatos.

\section{Sistemas de control}

Normalmente, el resultado de una campaña de publicidad se mide por las cifras. En una campaña electoral se puede medir con encuestas de opinión, si la intención de voto se incrementa, se considera que la campaña va por buen camino, este indicador se establece calculando la relación entre la intención de voto inicial y la intención de voto en varios periodos, durante y al final de la campaña; se deben diseñar otros tipos de indicadores, como la visibilidad y el conocimiento del candidato a medida que transcurre la campaña. Los resultados de estas continuas mediciones permitirán establecer correcciones del rumbo si no son los esperados.

Hoy en día, gracias a la analítica que nos aporta Internet, sabemos si se cumplen los objetivos fijados inicialmente en el brief. En campañas con poco presupuesto, como las de edilato, se puede realizar el 
control a través de las redes sociales, analizando las cifras, cantidad de likes, fans y comentarios que se generen a partir del lanzamiento de la campaña.

Sea cual sea el presupuesto para realizar la publicidad de la campaña, la Figura 7 nos muestra los pasos a seguir para diseñar una estrategia que aumente la posibilidad de éxito, es decir, que nos garantice en gran medida el cumplimiento de los objetivos. 
Figura 7. La campaña de publicidad

\section{CAMPAÑA DE PUBLICIDAD}

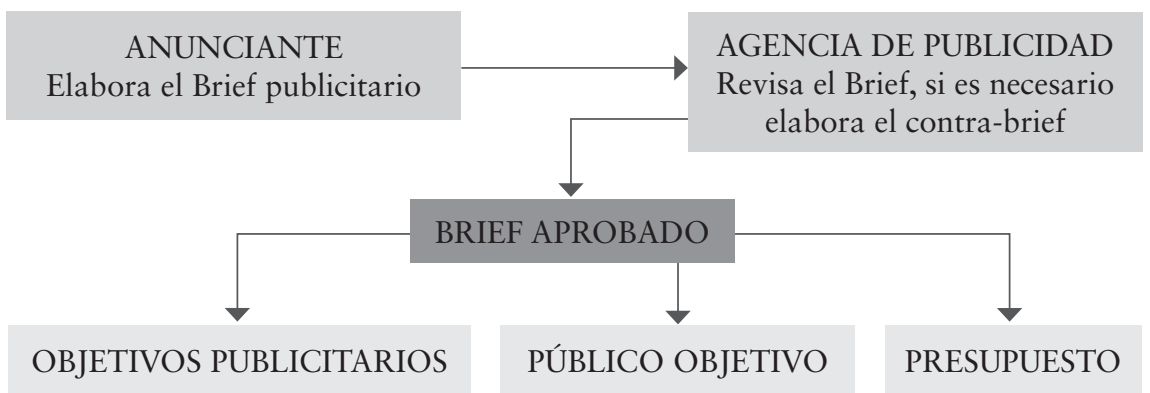

\section{ELABORACIÓN DE LA CAMPAÑA}

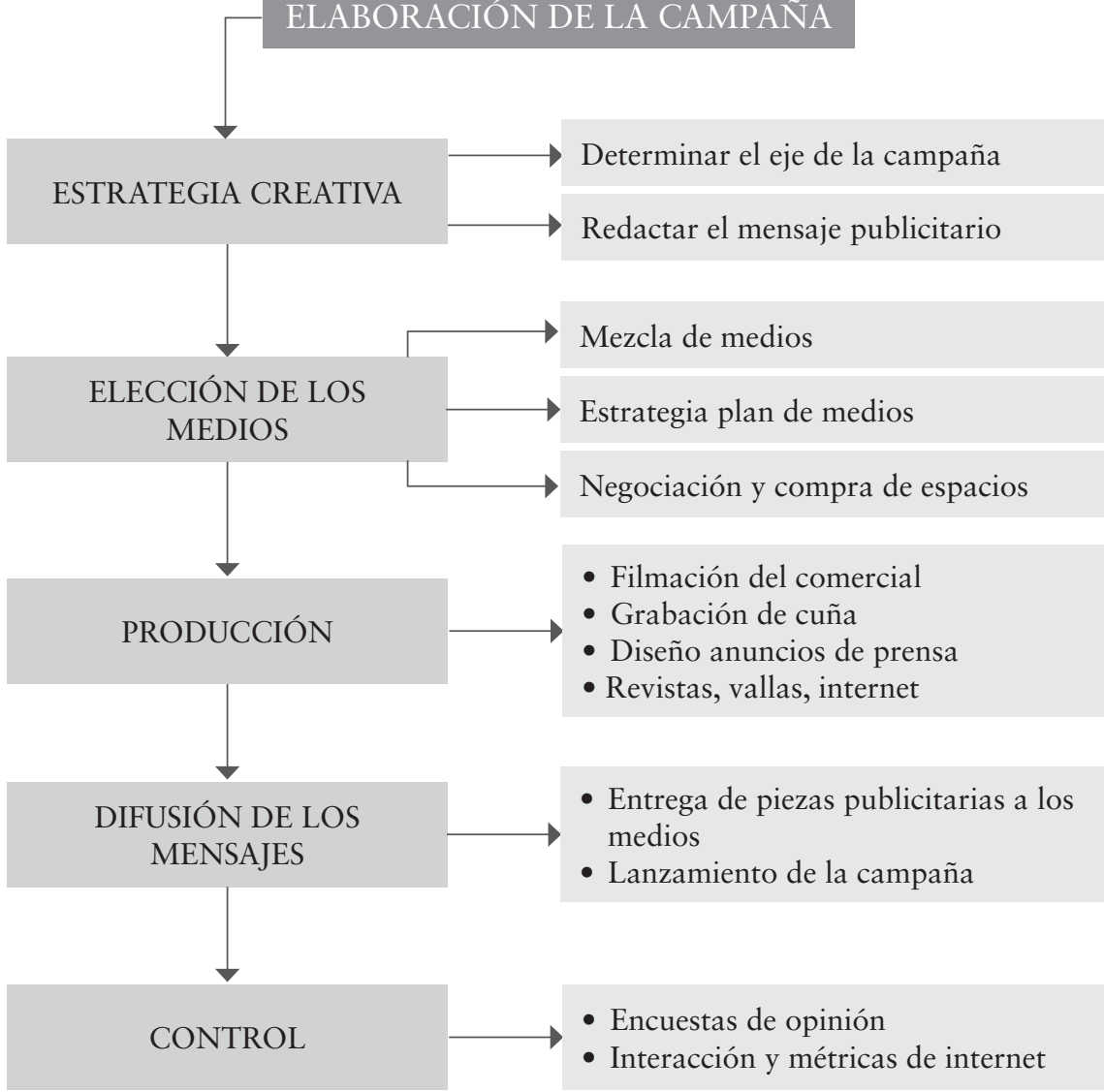

Fuente: elaboración propia. 


\section{Referencias}

Aira, T. (2015). La comunicación política. Madrid, España: Editorial UOC. Disponible en http://www.ebrary.com

Andreasen, A. (1995). Marketing Social Change: Changing Behavior to Promote Health, Social Development, and the Environment. San Francisco: Jossey-Bass Publishers.

Asensio, R. P. (2010). Marketing municipal. Madrid, España: Ediciones Díaz de Santos. Disponible en http://www.ebrary.com

Berrocal, S., Abad, L., y Cebrián, E. (2003). Comunicación politica en televisión y nuevos medios. Madrid, España: Editorial Ariel. Disponible en http://www.ebrary.com

Ferré, J. M., y Ferré, J. (1996). Politicas y estrategias de comunicación y publicidad. Madrid, España: Editorial Díaz de Santos.

Gutiérrez, A. (2015). La transformación digital y móvil de la comunicación política. Madrid: Editorial Ariel y Fundación Telefónica, en colaboración con Editorial Planeta. Disponible en http://www.fundaciontelefonica.com/arte_cultura/publicaciones-listado/pagina-item-publicaciones/ itempubli/334/

Hernández, C., Del Olmo, R., y García, J. (2000). El plan de marketing estratégico. Barcelona: Editorial Gestión 2000.

Kotler, P., Cámara, D., Grande, I., y Cruz, I. (2002). Dirección de marketing $\left(10^{a}\right.$. Ed.). Madrid, España: Editorial Prentice Hall.

López, B. J. M., y López, B. L. M. (2012). Investigación de mercados turísticos. Madrid, España: Larousse y Ediciones Pirámide. Disponible en http://www.ebrary.com

Luque, T. (2004). Marketing Político. Un análisis de intercambio político. Buenos Aires, Argentina: Editorial Ariel. Disponible en http://www.ebrary.com

Maarek, P. (2009). Marketing Político y comunicación. Barcelona, España: Editorial Paidós Ibérica.

Manes, J. (1997). Marketing para instituciones educativas. Barcelona, España: Editorial Granica.

Martín Salgado, L. (2002). Marketing político: arte y ciencia de la persuasión en democracia. Madrid, España: Editorial Paidós Ibérica. 
Mazzoleni, G. (2014). La comunicación política. Madrid, España: Larousse y Alianza Editorial. Disponible en http://www.ebrary.com

Orosa, J. J. (2009). El marketing de los partidos politicos. Barcelona, España: Erasmus Ediciones.

Puon, L. (2013, diciembre). Definición de publicidad. Merca2.0. Recuperado de http://www.merca20.com/definicion-de-publicidad/

Prieto, H. J. E. (2009). Investigación de mercados. Bogotá, Colombia: Ecoe Ediciones. Disponible en http://www.ebrary.com

Ruiz, O. J. I. (2012). Teoría y práctica de la investigación cualitativa. Bilbao, España: Publicaciones de la Universidad de Deusto. Disponible en http:// www.ebrary.com 
